\title{
Águas subterrâneas: Um estudo acerca da superexplotação sobre a microbacia III do Rio Salgado
}

\section{Groundwater: A study about overexploitation on the watershed III River Salgado}

\author{
Maria Aparecida Pereira Santos ${ }^{1}$ Vagner Sales dos Santoss ${ }^{2}$ Raimunda Moreira da Franca ${ }^{3}$ Michele da Silva Chaves ${ }^{4}$
}

Resumo: A Microbacia III do rio Salgado é uma das cinco microbacias que compõem a sub-bacia do salgado e está situada ao sudoeste do Estado do Ceará, sendo esta a que mais utiliza as águas subterrâneas do aquífero médio. Este trabalho retrata a problemática das águas subterrâneas visando à superexplotação, e com a finalidade estabelecer debate e discutir sobre a maneira mais racional para o uso consciente das águas da área de estudo. Devido à prática de determinadas atividades, temos impactos negativos sobre as águas subterrâneas da referida região que afetam diretamente na sua quantidade provocando rebaixamento do nível freático do aquífero. Utilizando referencial teórico, podem-se avaliar as condições do recurso hídrico e propor recomendações. Os resultados apontam que hoje temos um percentual de área com 20,92\% que estão comprometidos com nível de rebaixamento de 20 metros. Medidas precisam ser tomadas antes que as consequências sejam irreversíveis ao recurso e os instrumentos do âmbito legal necessitam de uma efetiva aplicabilidade para evitar que esse contexto se aplique para outras áreas.

Palavras-chaves: Manancial, qualidade de água, rebaixamento, nível freático.

\begin{abstract}
The Watershed III of the Salt River is one of five watersheds that make up the salty sub-basin and is located southwest of Ceará, which is the one that uses the underground middle aquifer waters. This work depicts the problem of groundwater order to overexploitation, and in order to establish debate and discuss the most rational way to the conscious use of the study area waters. Due to the practice of certain activities, we have negative impacts on groundwater in that region that directly affect the quantity causing lowering of the water level of the aquifer. Using theoretical framework, one can evaluate the condition of water resources and propose recommendations. The results show that today we have an area percentage with $20.92 \%$ who are committed drawdown of 20 meters. Measures need to be taken before the consequences are irreversible the appeal and the instruments of the legal framework require an effective applicability to prevent this context applies to other areas.
\end{abstract}

Key words: Watershed, groundwater overexploitation, demotion, water table.

\footnotetext{
*Autor para correspondência

Recebido para publicação em 02/08/2015; aprovado em 10/10/2015

${ }^{1}$ Tecnologa em Saneamento Ambiental, Faculdade de Tecnologia Centec - Fatec - CARIRI; (88) 8863-5889, adriellypereyra@ hotmail.com

${ }^{2}$ Mestre em Engenharia Civil e Ambiental, Professor da Faculdade de Tecnologia Centec - Fatec - CARIRI; Vagner_saneamento@yahoo.com.br

${ }^{3}$ Mestre em Saneamento Ambiental, Professora da Faculdade de Tecnologia Centec - Fatec - CARIRI; francacariri@yahoo.com.br

${ }^{4}$ Especialista em Saúde e Meio Ambiente, Professora da Faculdade de Tecnologia Centec - Fatec - CARIRI, michelechaves@ hotmail.com
} 


\section{INTRODUÇÃO}

A água subterrânea constitui cerca de $90 \%$ da água doce do nosso planeta. Apenas 5\% formam todos os rios, lagos e outros. Esses números mostram a importância fundamental das águas subterrâneas (HOLANDA, 2003).

A região se localiza na porção sudeste do Ceará bordejando a chapada do Araripe, situa-se um nível altimétrico de $450 \mathrm{~m}$, ocupando uma extensão territorial de $2442 \mathrm{~km}^{2}$. E caracterizado por extensos planos modelados em rochas sedimentares com conglomerados, arenitos, filítos, calcífilos e fossilíferos (IBGE, 2011).

O Brasil um país de dimensões continentais que apresenta uma área superficial de $8.515 .767,049 \mathrm{~km}^{2}$ (IBGE, 2010), possui uma grande diversidade de ecossistemas e climas, e que tem imensa capacidade hidrológica. Apesar disso há uma despreocupação pelo valor desse bem tal importante para vida e equilíbrio ecológico, que é a água. De acordo com o Decreto 31.077, de 12 dez. de 2012, “água é uma substância química líquida, incolor, inodora, composta por duas partes de hidrogênio e uma de oxigênio $\left(\mathrm{H}_{2} \mathrm{O}\right)$, que forma os rios, lagos, o mar e também grande parte dos organismos".

A maior reserva de água subterrânea do estado do Ceará está localizada na Bacia sedimentar do Araripe, porção sul do estado, na divisa com Pernambuco e Piauí. O relevo é constituído por dois domínios principais, planaltos e depressão, conhecidos como Chapada do Araripe e vale do Cariri, respectivamente. Cobre uma área de $11.000 \mathrm{Km}^{2}$, de forma aproximadamente elíptica, cujo eixo maior se dispõe de leste para oeste, com extensão de ordem de 170-180 km, largura 50-70 km com níveis altimétrico em torno de 850$900 \mathrm{~m}$. No lado cearense as águas drenam as sub-bacias hidrográficas do Alto Jaguaribe e do Salgado. Possui poços com vazão da faixa de 5 a $200 \mathrm{~m}^{2} / \mathrm{h}$ para profundidade de 50 a $300 \mathrm{~m}$ (COGERH, 2011).

Quando a extração da água subterrânea ultrapassa a recarga natural por longos períodos de tempo, os aquíferos sofrem depleção e o lençol freático começa a baixar (SEMADS 2001).

Para Simonato (2008), a superexplotação caracteriza-se pela demanda superior à disponibilidade e é refletida através da diminuição dos níveis potenciométricos dos poços e queda na produção de água. As consequências associadas a este problema podem ser, entre outros:

1. Econômicas - maior custo de exploração, devido à maior profundidade do nível de água; perda de poços por tornarem-se secos ou com baixíssima produção; necessidade de trazer água de local mais distante;

2. Ambientais - alteração na qualidade da água devido a desequilíbrios físico-químicos causados pelo bombeamento excessivo do aquífero;

3. Estruturais - acomodações de solo que podem provocar desabamentos de relevo, bem como de edificações, em decorrência de alívios de pressão ocasionados pela remoção de grandes volumes de água.

No estado do Ceará uma região, a qual está sofrendo impactos negativos em seus mananciais é a sub-bacia do rio Salgado. As águas superficiais e subterrâneas da supracitada sub-bacia encontram-se comprometidas, fato esse citado em estudos como os de Fernandes (2002) e Costa (2012) provocando alterações na água e pondo em risco os diversos usos desta.

O objetivo do presente trabalho é estudar a área da Micro-bacia III do salgado e verificar sua vulnerabilidade acerca da superexplotação, ressaltando sua importância com vista a colaborar para preservação e conservação.

\section{MATERIAL E MÉTODOS}

Quanto à metodologia da pesquisa, utilizou-se dois tipos: A descritiva que segundo Prestes (2008) o qual, se observa, registra, analisa, classifica e interpreta os fatos sem que o pesquisador lhe faça qualquer interferência. Assim o pesquisador estuda os fenômenos do mundo físico e humano, mas não os manipula. Na pesquisa descritiva tem como objetivo principal a descrição das características de determinada população ou fenômeno ou então o estabelecimento de relações entre variantes (GIL, 2009).

A pesquisa tem também um enfoque exploratório, pois para o desenvolvimento do projeto que se configura com o objetivo de proporcionar maiores informações sobre o assunto que vai ser estudado, facilitando a delimitação do tema a ser pesquisado (PRESTES 2008).

Realizou-se pesquisa de gabinete e/ou documentais em órgãos responsáveis pelo gerenciamento de recursos hídricos, como a Companhia de Gerenciamento de Recursos Hídricos COGERH, também foram analisados, livros, artigos científicos, revistas impressas e/ou eletrônicas, teses e dissertações de mestrado e doutorado, bancos de dados online como: Scielo, sites, portais de notícias, etc.

\section{CARACTERIZAÇÃO DA ÁREA DE ESTUDO}

A Sub-Bacia do Salgado integra a Bacia do Rio Jaguaribe. Encontra-se localizada no sul do Ceará e possui uma área de drenagem de $12.865 \mathrm{~km}^{2}$, o equivalente a $8,5 \%$ de seu território, sendo Salgado o principal rio, com $308 \mathrm{~km}$ de extensão. Essa sub-bacia é composta por 23 municípios. Devido à sua abrangência foi dividida em cinco Micro-bacias. A área de estudo é a Micro-bacia III do salgado que engloba os municípios de Juazeiro do Norte, Barbalha, Crato, Caririaçu e Jardim.

Figura 1 - Área de abrangência da Micro-bacia III Salgado,

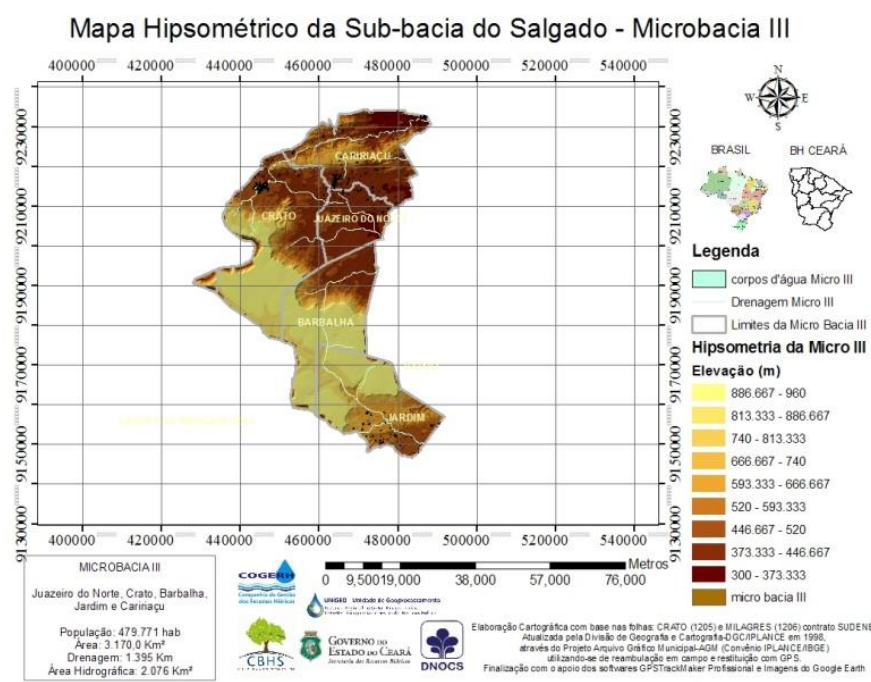

Fonte: COGERH, 2015 
Dos cinco municípios que estão dentro dadas MicrobaciasIII, o de Juazeiro do Norte é que apresenta maior concentração populacional e também o que mais tem poços perfurados. Onde o principal uso dos recursos hídricos é para abastecimento humano e industrial, criação de animais e irrigação das plantações da região. Devido à perenidade dos rios e como forma de garantir o abastecimento as comunidades, há a perfuração de poços (Cartilha CSBH Salgado, 2010).

\section{INSTRUMENTOS LEGAIS E DE GESTÃO}

Como instrumento legal para uso da água, no Brasil tem-se a Lei $N^{\circ}$ 9.433, de 8 de Janeiro de 1997, que institui a Política Nacional de Recursos Hídricos (PNRH), a qual, tem como objetivos: "assegurar a atual e as futuras gerações a demanda de água com qualidade, de modo que seja um uso racional, prevenindo o uso inadequado, com vistas ao desenvolvimento sustentável".

No artigo $33^{\circ}$ da Lei $\mathrm{N}^{\circ} 9.433$, inciso 3, está previsto que os Comitês de Bacias Hidrográficas, um dos integrantes do Sistema Nacional de Gerenciamento de Recursos Hídricos, tem como função gerir o uso da água, aprovar o PNRH da bacia, promover o debate das questões relacionadas a bacia e estabelecer o custo para o uso dos recursos hídricos. O Comitê da Sub-bacia Hidrográfica do Rio Salgado - CSBH Salgado foi criado pelo Decreto $n^{\circ} 26.603$ de 14 de maio de 2002 e instalado em 10 de julho de 2002 (CSBH Salgado, 2010).

A Companhia de Gestão de Recursos Hídricos (COGERH), foi criada pela política de Recursos Hídricos do Governo do Estado, é a responsável pelo gerenciamento e disciplinamento de mais de $90 \%$ das águas acumuladas no estado, de forma descentralizada, integrada e participativa.

A Companhia das Águas, outro órgão gestor que auxilia a COGERH, foi criada pela Lei $\mathrm{n}^{\circ} 12.217$, de 18 de novembro de 1993, com a finalidade de implantar um sistema de gerenciamento da oferta de água superficial e subterrânea do Estado do Ceará, compreendendo os aspectos de monitoramento dos reservatórios e poços, manutenção, operação de obras hídricas e organização de usuários nas 12 bacias hidrográficas do Ceará. Através da informação e divulgação de dados à comunidade, a respeito dos recursos hídricos, a Companhia das Águas junto a COGERH tomam decisões coletivas e negociadas, como também avaliam a política de gestão a ser implementada nas bacias (Portal COGERH).

\section{RESULTADOS E DISCUSSÃO}

Há a presença de um polo industrial localizado no Triângulo Crajubar, denominação da dada a integração das cidades de Crato, Juazeiro e Barbalha, que apesar de ser um potencial econômico para a região, pode comprometer a quantidade dos recursos hídricos superficiais e subterrâneos. Conforme mapa a seguir mostra a delimitação da área com maior nível de superexplotação segundo estudos realizados pela COGERH e colaboradores.

A problemática do uso da Micro-bacia III está no uso indiscriminado da água bruta, visto que os instrumentos de gestão não englobam de forma concreta e direta.

Figura 2 - Área do estudo destacando perímetro com superexplotação

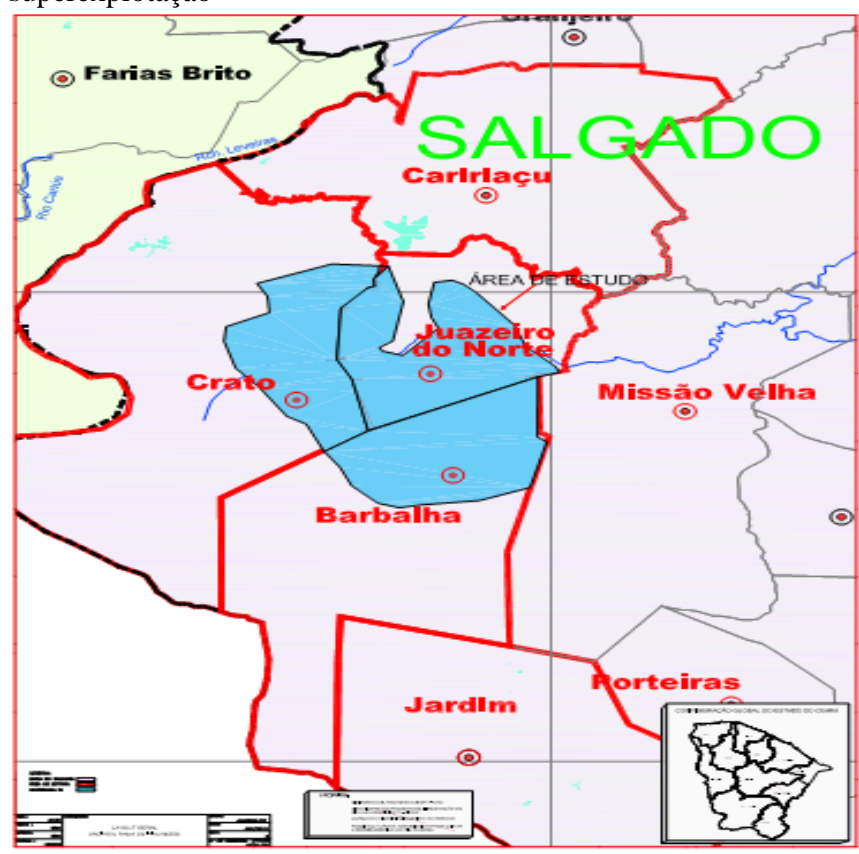

Fonte: COGERH, 2015.

Tabela 1-Dados dos munícipios do estudo.

\begin{tabular}{lccccc}
\hline Municípios & $\begin{array}{c}\text { Total de poços } \\
\text { (SIAGAS, 2015). }\end{array}$ & $\begin{array}{c}\text { Hectares com } \\
\text { superexplotação (COGERH, } \\
\text { 2015). }\end{array}$ & $\begin{array}{c}\text { Perímetro com } \\
\text { superexplotação (COGERH, } \\
\text { 2015). }\end{array}$ & $\begin{array}{c}\text { Área total } \\
\text { domunícipio } \\
\left(\mathrm{KM}^{2}\right)\end{array}$ & $\begin{array}{c}\text { População } \\
\text { IBGE } \\
(2012)\end{array}$ \\
\hline Caririaçu & 39 & & & 623,564 & 26.840 \\
Crato & 237 & 12.700 & 56.658 & $1.176,47$ & 127.657 \\
Barbalha & 205 & 14.121 & 50.587 & 569,508 & 58.347 \\
Juazeiro do Norte & 337 & 14.925 & 68.658 & 248,832 & 263.704 \\
Jardim & 75 & & & 552,424 & 27.069 \\
\hline
\end{tabular}

Segundo um relatório inédito da COGERH, O monitoramento do ano de 2013 apresentou um resultado negativo, no que diz respeito à recuperação dos níveis de água dos aquíferos apresentando rebaixamentos médio regional de 4,75m. Repetindo a desempenho negativa de 2012, em 2013 todos os poços tiveram rebaixamento do nível estático, com mínimo de 1,33 m chegando ao máximo 22,41 m. Este comportamento deve ser resposta à baixa precipitação todo estada do Ceará, que não permitiu recuperação dos aquíferos, portanto um bombeamento que superou a infiltração e o consumo crescente devido à seca.

De acordo com Veríssimo et al., (2005) a vulnerabilidade dos terrenos do Vale do Cariri é alta, possuindo vulnerabilidade moderada apenas nas áreas onde afloram o Sistema de Aquífero inferior. O Trabalho de Tavares et A., (2009) confirma esses estudos anteriores. A 
fragilidade do manancial subterrâneo do Vale do Cariri implica na necessidade de adoção de políticas municipais de zoneamento para ocupação ordenada dos espaços urbanos e na urgência de implantação de estações de tratamento de esgotos domésticos e industriais, coleta seletiva dos resíduos sólidos e construção de um aterro regional.

Em um modelo de gestão sustentável há diretrizes para um conjunto de instrumentos primordiais, tais como: uma base de informações socialmente acessível, definição clara dos direitos de uso, controle dos impactos sobre o sistema hídrico e o processo de tomada de decisão.
Analisando estudos anteriores como o de Tavares, e correlacionando dados, podemos verificar que temos uma área de 41.746 ha em um perímetro de 175.903, que engloba os munícipios de Juazeiro do norte, Barbalha e Crato, com rebaixamento no nível freático maior que $20 \mathrm{~m}$, esses dado informa que da área total do munícipios temos que, 20,92\% está vulnerável com rebaixamento comprometendo o uso essas águas é podendo trazer várias impactos ambientais para o ecossistema da área, conforme mostra o Figura 1.

Figura 1. Área vulnerável devido rebaixamento do lençol freático X Área total do município.

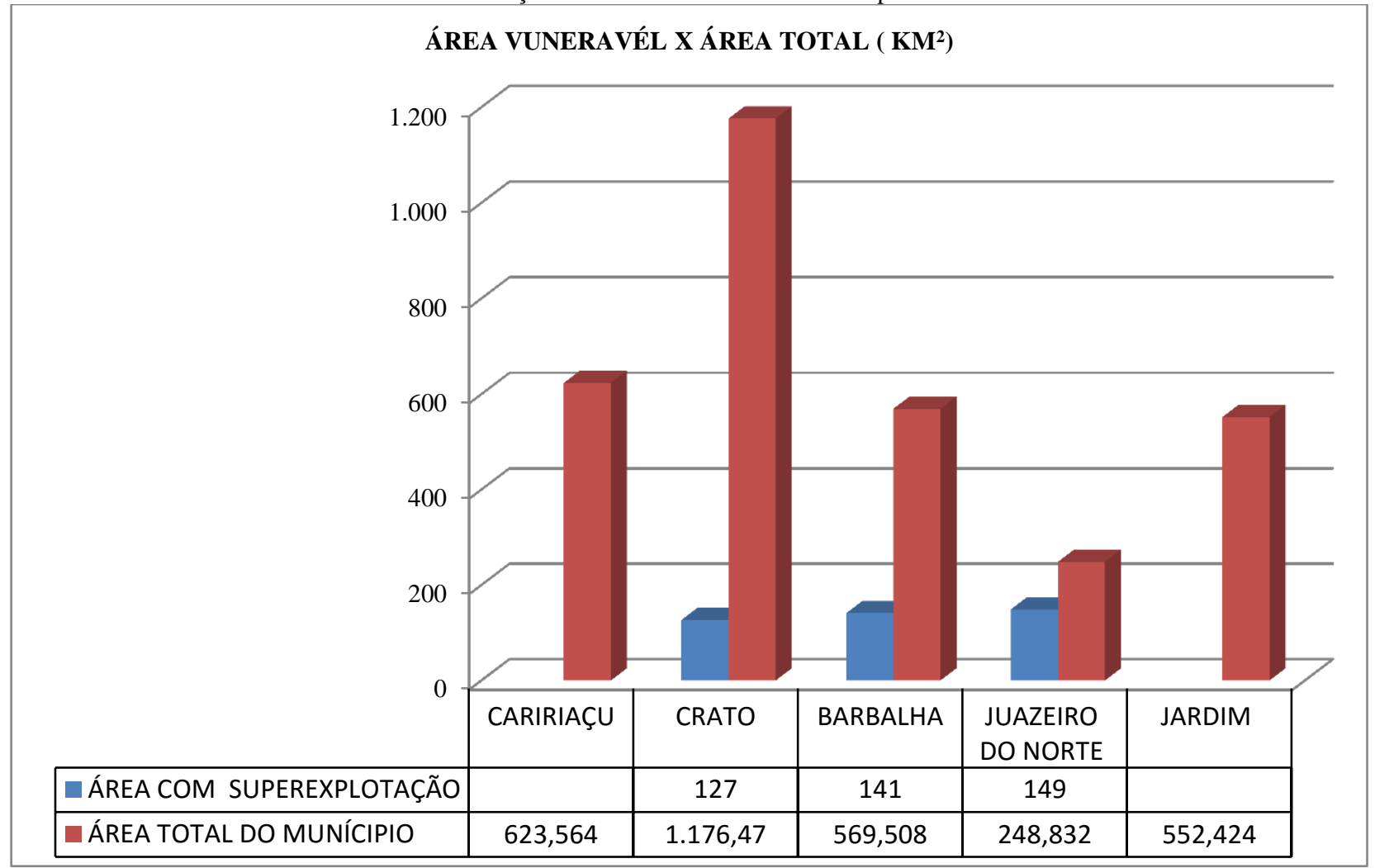

\section{CONCLUSÕES}

Considerando a crescente utilização das águas subterrâneas principalmente para o abastecimento público, estudos que visam demonstrar como funciona a sistemática de utilização e como as águas estão reagindo a inúmeras ações, são de fundamental importância para que programas de proteção das águas subterrâneas sejam implementados, fatores que estão influenciados quantitativamente e qualitativamente necessitam de estudos aprofundados e pesquisas sistemáticas em longo prazo. Um monitoramento efetivo do recurso e divulgação junto à sociedade faz parte do processo para evitar consequências danosas aos aquíferos, levando em consideração que os instrumentos de gestão podem auxiliar na construção dos mecanismos de gestão compartilhada. Esse último aspecto de grande importância, uma vez que temos águas, repartindo os interesses hídricos do estado. A região encontra-se afetada, mas com a aplicação adequada dessas medidas atrelando as ferramentas de gestão, a Micro-bacia III do Salgado pode-se manter em boas condições ambientais.

\section{REFERÊNCIAS BIBLIOGRÁFICAS}

CARTILHA INFORMATIVA HIDROAMBIENTAL. Comité da Sub-Bacia do Salgado. Fortaleza 2010.

CARTILHA INFORMATIVA. Águas subterrâneas bacia doAraripe.Fortaleza 2011.

COGERH - Companhia de Gestão de Recursos Hídricos. Apresentação. Disponível em: <http://portal.cogerh.com.br/categoria1>. Acessado em 22 de maio de 2014.

COSTA, C. T., DOS SANTOS, E. F., \& TAVARES, P. R. L. Potencialidade da contaminação por metais pesados procedente da indústria galvânica no município de juazeiro do norte/ce. Águas Subterrâneas. 2012, Disponível em <http://www.urca.br/coloquioeconomia/IIcoloquio/anais/tr ab_territ_meio_amb/2.pdf> 
FERNANDES, G. B. Caracterização qualitativa das águas do Rio Salgado no município de Juazeiro do Norte, Ceará. In: Simpósio Ítalo Brasileiro de Engenharia Sanitária e Ambiental,VI, 2002, Vitória, Espírito Santo, Brasil. Anais p. 1-9., 2002.

GIL. A. C. Como elaborar projetos de pesquisa. 4. Ed. São Paulo: Atlas, 2009.

HOLANDA, F. J.M. Uso e manejo dos recursos naturais no semiárido. Fortaleza: Edição do autor, 2003.

IBGE - Instituto Brasileiro de Geografia e Estatísticas Cidades. Mapa das Informações Básicas dos Municípios. 2010. Disponível em: <http://www.cidades.ibge.gov.br/download/mapa_e_muni cipios. php?lang=\&uf=ce $>$. Acessado em 22 de maio. 2014.

NASCIMENTO, D. C.; ALVES, C. C. E.;CHACON, S. S.; ROCHA, G. A.; Problemática Hidrológica De Juazeiro Do Norte - Ce: Panorama Atual E Impactos Ambiental Na Sub-Bacia Do Rio Salgado .In: I Colóquio Sociedade, Políticas Públicas, Cultura e Desenvolvimento-CEURCA, ISSN 2316-3089.Universidade Regional do Cariri URCA, Crato - Ceará - Brasil. 2012. Disponível em: <http://www.urca.br/coloquioeconomia/IIcoloquio/anais/tr ab_territ_meio_amb/2.pdf $>$.
PRESTES, M. L. M. A pesquisa e a construção de conhecimento científico. São Paulo: Rêspel, 2008.

RIBEIRO, M. L.; LOURENCETTI, C.; PEREIRA, S. Y.; MARCHI, M. R. R. Contaminação de águas subterrâneas por pesticidas: avaliação preliminar. Química Nova, v. 30, n. 3, 2007.

SEMADS. Secretária de estado de meio Ambiente e desenvolvimento sustentável. Poços tubulares e outras captações de água subterrânea. Orientação aos Usuários.SEINPE - Secretaria de Estado de Energia da Indústria Naval e do Petróleo Departamento,Rio de Janeiro 2001.

SIMONATO. M. Água subterrânea em áreas urbanas: potencialidade, problemas e desafios. Geociênc. (São Paulo) v.27 n.1 São Paulo jan./mar. 2008. Disponível em:<http://ppegeo.igc.usp.br/scielo. >acessado em 11 de junho de 2015 .

SOHIDRA. Superintendência de obras hidráulicas. Diretoria de Águas Subterrâneas - DASUB. Disponível em $<$ :http://www.sohidra.ce.gov.br/index.php/aguassubterraneas> Acessado em 20 de maio 2014. 